\title{
The Neverending Story-Using the Narrative as a Fundamental Approach to Teaching Biology and Beyond
}

\author{
Marcus Kumala
}

Published online: 8 October 2010

(C) Springer Science+Business Media, LLC 2010

\begin{abstract}
Topics typically relegated to the realms of "microbiology" are often difficult challenges to student engagement and learning. Here I discuss the rationale for utilizing the universal narrative as an effective teaching strategy to teach all aspects of science, with a particular emphasis on biology topics regularly mandated at the senior level. This article serves as an introduction or extended abstract for several biological narratives with an emphasis on the origin and diversification of life. These can be found online in their entirety under the title of "The Neverending Story-The Origin and Diversification of Life."
\end{abstract}

Keywords Universal narrative · Microbiology - Origin of life $\cdot$ Diversity of life $\cdot$ Co-option

"Teacher, where did life come from? Why do we have a nucleus? Why do we have DNA? Why do plants have chloroplasts? Do you remember all the steps to the citric acid cycle? Which came first, the chicken or the egg? What is that animal doing to the other one? Why do we have to study this?"

Left to its own devices, biology class - well, any science classroom - quickly becomes a breeding ground for questions that can leave its resident teacher smiling, blushing, shell-shocked or, worse, repressive. The last is often an unfortunate consequence of how difficult it can be to keep up with the "newest discoveries," which seemingly alter our understanding of the world around us in very drastic ways. In reality, they are merely adding the latest wrinkle to what should be a familiar face to everyone.

M. Kumala $(\bowtie)$

33 Hillbeck Crescent,

Toronto, ON M1B 2M8, Canada

e-mail: Mkumala@gmail.com
It is the lack of a strong connection to older, and yet still relevant ideas, that can lead to both reluctance and apprehension when presented with the challenge of assimilating new knowledge laced with the newest jargon. For the most part, teachers are not experts in the field, and yet they are responsible, nay, mandated to disseminate up-todate information to students, which is often hidden away at a doctorate's level of literacy. One has to sympathize with a teacher specialized in, say, kinesiology who is asked to teach a grade 12 biology course that is heavily infused with organic chemistry and microbiology. A teacher in such a scenario may feel completely overwhelmed trying to simply master the "general" textbook concepts, let alone provide students with an enriching context in which to learn them; no small feat when you begin to pair the daily challenges of teaching high school with the proclivities of academics to write as if they've just discovered sliced bread again. So how can we as mutually concerned educators and professional scientists better serve one another and our future voting populations for that matter? Perhaps by giving students and teachers a conceptual lifeline, by teaching science-biology in particular-as the context-driven history courses they were meant to be. That is true outreach.

As in the classical sense of the term, the history of the universe and our vested interest in a condition known simply as "life" contains tales of both epic triumphs and disasters against a backdrop of unforeseen stasis, innovation, and loss. But perhaps more evident within the sciences than the humanities, natural history, if taken as a whole, remains our noble attempt to discover a universal paradigm that explains these vast phenomena and not the other way around. Case in point, the debate of whether or not genes or metabolism arose first will likely, though not necessarily, cause far fewer chairs being thrown than speculating on, say, the ethnocultural membership of Alexander the Great 
(sorry, I went to a high school with a lot of Greeks and Macedonians). Fortunately, as in other history courses, the key to unlocking many of the more complicated mysteries of life may be found in our understanding of the sequence of events leading up to pivotal moments in time. For example, the chronology of World War II may not fully elucidate the ideological conflict between global superpowers, but Hitler invading Poland in 1939 is still a vital piece of a larger framework to further explore the war in depth.

Likewise, understanding the emergence of the major features that characterize life and the universe may provide students with the necessary traction to successfully navigate our science curricula, which frequently demands a firm grasp of expert information. This is quite evident in senior biology classes that require mastery of many concepts at the microbiological level, such as DNA replication, transcription and translation, and cell respiration/photosynthesis, and yet remain poorly rooted to fundamental units taught at lower grade levels, like the principles of evolution and the diversity of life. Featured below are excerpts from seven chapters available online to help illustrate how the universal narrative can be used to approach some of the more conceptually difficult ideas in biology. The primary focus is on reconciling common memorization- and applicationheavy microbiology topics to the origin and diversification of life so we are left with an unbroken continuity from the beginning to the present and beyond (see Fig. 1):

Life originating in deep-sea vents had several things going for it: For one, it shifted the location of the origin of life away from ongoing debates about the "actual" composition of early earth's atmosphere by virtue of its own reducing microenvironment. More importantly perhaps, it may have offered life a safe haven from the potentially destructive UV rays and the late heavy bombardment of meteors, which otherwise could have delayed the emergence of life until about 3.9 or 3.8 billion years ago. So, while some scoured the skies or simply their pots, others combed the deep once again for subtler alternatives with more explanatory power.

They found one in the form of another type of hydrothermal vent system located a few kilometres away from seafloor spread-zones. Hydrothermal "chimneys" churn out a similar chemically rich effluent as their smoker cousins, but at the more hospitable $40-90^{\circ} \mathrm{C}$ range and, most importantly, in the presence of stacked microcaverns coated with, you guessed it, catalytic iron and nickel monosulfides (FeS, NiS). When hot, reduced hydrothermal fluid meets cool, $\mathrm{CO}_{2}$-rich ocean water, several interesting reactions take place... (Chapter II-“Soup that eats like a meal") Kumala and Brooks (2010).

RNA is a robust retort to the teleological notion that "Form follows function" because it is a molecular multitool, the 'spork' to the classic chicken or the egg or forkspoon scenario perpetuated by the horribly coined 'Central Dogma' of molecular biology. You know, the one that goes "Information flows from DNA to RNA to proteins, but if proteins are required to make DNA, which came...'It is not difficult to envision a time when life (or something very close to it) consisted of diverse assemblages of RNA molecules, or 'selfish cooperators' if you will: splicers, binders, replicators, and even manufacturers. The ribosome is after all fundamentally a ribozyme! Although proteins stabilize and increase the efficiency of modern day ribosomes, rRNA is the catalyst responsible for forming the peptide bonds that link amino acids together... (Chapter I- "Life's Spork") Kumala and Brooks (2010).

So is the Primordial Flu a reality or simply a loss of phylogenetic signal? It's really hard to tell. If the basic narrative is indeed accurate, however, we now know that textbook RNA translation and the genetic code evolved BEFORE transcription and way earlier than DNA and DNA replication. In other words, the flow of biological information evolved in the exact OPPOSITE direction than proposed by the 'Central Dogma of Molecular Biology' and 'reverse transcription' is actually the original condition! Only after integration within the host RNA cell did today's division of labour emerge where DNA plays the role of hereditary molecule, proteins perform the bulk of catalysis, and RNA provides 'scaffolding,' while it quietly micromanages in the background; pretty remarkable when you think about it... (Chapter III-"Flu Season") Kumala and Brooks (2010).

Metabolism is the sum of all the catabolic AND anabolic chemical reactions in a cell $(\sim 1,000)$ catalyzed by proteins called enzymes. These reactions are distributed amongst a universal set of about 50 pathways despite whatever additional metabolic specializations may be found amidst the incredible diversity of life on our planet, which also implies the predominantly vertical inheritance of these paths since the last universal common ancestor (or, LUCA). The vast majority of these 'core' pathways involve carbohydrates (i.e. glycolysis, gluconeogenesis, pyruvate metabolism, the pentose-phosphate cycle, etc.), amino acids, fatty acids (but not membrane lipids), and nucleotides, as well as cofactors and vitamins, the Citric Acid Cycle, and enzymes and coenzymes involved in energy transfer. If we then attempted to 


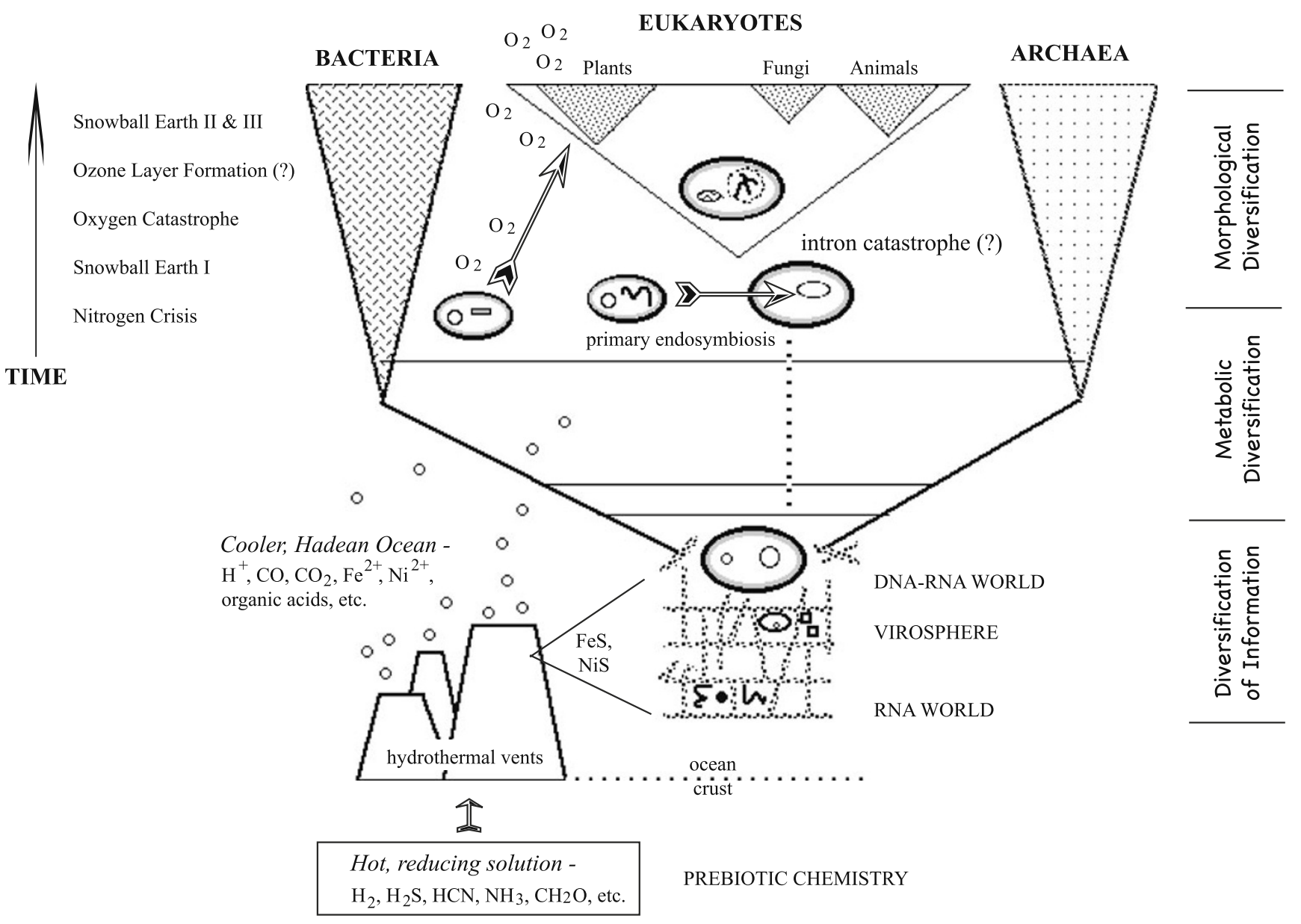

Fig. 1 The origin and diversification of life

create a 'metabolic map' of this universal set, we would be left with a proverbial labyrinth of twists and turns that eventually converge at the Citric Acid Cycle. Now when faced with the reality of universal metabolism, one's natural inclination is to play intellectual 'hooky' and do one of two things: You will either see this as clear evidence for common descent and accept that these paths evolved 'somehow' in the distant past OR you will see it as an 'irreducibly complex' phenomenon that has been mysteriously stamped onto all life forms big and small. Luckily, there are a handful of more curious minds that have taken the challenge of untangling this potential Gordian knot. (Chapter IV_-"You going to pay me to eat that?") Kumala and Brooks (2010).

To make matters worse, nitrogenase is incredibly oxygen sensitive! At present $\mathrm{O}_{2}$ concentrations, cyanobacteria lose approximately $30 \%$ of their nitrogenase activity as the Fe-S clusters become oxidized and the solution is to simply make more of the enzyme, which further strains the nitrogen economy. The same can be said about the enzyme rubisco, where upwards of $40 \%$ of its activity is oxygenase in a typical $\mathrm{C} 3$ plant and the solution is once again to make more! Unsurprisingly, it may be the world's most abundant protein. Even the proteins involved in the water splitting complex of PSII (i.e. D1) struggle with the task at hand and become irreversibly damaged after exposure to oxygen and must be replaced about every 10,000 electron transfers. These examples are often referred to as 'frozen metabolic accidents,' and ironically this is not far from the truth...(Chapter V- "Why excuse me! Was it something I ate?") Kumala and Brooks (2010).

If reports are true, it appears that a run-of-the-mill archaeon either engulfed or was infiltrated by a relative of present-day $\alpha$-proteobacteria, perhaps similar to extant Rickettsia species or purple nonsulphur bacteria. Once inside, either the host archaeon failed to digest the $\alpha$-proteobacterion or the $\alpha$ proteobacterion failed to complete its parasitic lifestyle and became a permanent resident. The descendants of this strange matrimony would give 
rise to the Eukarya (under the Eukaryotes-late hypothesis), and in some of our better-known lineages, the descendants of these $\alpha$-proteobacteria would become our mitochondria. Yes, believe or not, the organelle that 'super-charges' your cells originated from a symbiotic alliance that occurred anywhere between 2 and 1.5 billion years ago! And later, at a more exclusive gala, it appears that this Eukaryote conglomerate successfully proposed a similar merger with a cyanobacterium, and its descendants would one day become the plastids (chloroplasts, in particular) of algae, plants, and other photosynthetic 'protists' whose lineages independently went "shopping" for additional accessories. To think, organelle-level cellular organization emerged from perhaps the most extreme example of co-option: endosymbiosis ... (Chapter VI-“Guess who's coming to dinner? And staying...”) Kumala and Brooks (2010).

Prior to the second and third Snowball Earth events, single-cell on single-cell violence was mostly passive aggressive by today's standards - lots of chemical interference and a few poisonings but not a whole lot of mechanical stabbing and smashing. Sure, larger cells were capable of engulfing smaller ones (i.e. phagocytosis) but grazing pressures must have been limited due to restrictions on size, and I guess you could characterize life as mostly a drinking competition hosted by the local photoautotrophs. But the competition must have intensified during successive deep freezes, which would have created a situation where single-celled organisms experienced high cell densities and resource limitations; apparently the only scenario where multicellularity and the efficient use of a resource becomes a viable strategy, particularly for heterotrophs. Out of these dire conditions, it appears that one lineage of eukaryotes, one we're particularly fond of, formed a specific partnership that would transform the traditional 'Guess who's coming to dinner?' to more of a 'Guess who's going to be dinner?' kind of affair...(Chapter VII-“Life's Smorgasbord”) Kumala and Brooks (2010).

There is undoubtedly a far greater intrinsic value gained from a student's understanding and appreciating the historical context of how they came into existence versus expecting them to memorize each mind-numbing step of the citric acid cycle or every enzyme in the electron transport chain (not that any of us ever had to do that... ahem). The above are just some illustrations of how the narrative can be used to give context to the often disparate, conceptually challenging, and, frankly, intimidating topics that permeate "microbiology" expectations of your typical senior-level biology course. Moreover, when the emphasis is shifted toward a biological literacy of understanding and synthesis rather than mere knowledge of facts and application, tales of this nature serve to reinforce themes universal to life on our planet, namely homology, adaptation, cooption, selection, and suboptimal design, regardless of the scale of observation. If students are taught such a thematic framework to study the more accessible "macrobiological" (i.e., whole parts, organs, behaviors, etc.) dimension, it will undoubtedly prove easier to grasp similar examples at the molecular level. Under this paradigm, our mandate as biology teachers becomes a lot clearer. Instead of simply preparing our next generation of doctors and lab technicians, which will realistically embody just a small fraction of our student biota, let's give them what every citizen of our planet can truly learn to appreciate: Rome wasn't built in one day; neither were we. So let's build, or rather deconstruct, the four billion-year-old man.

In the classic Michael Ende novel The Neverending Story (1979), a mysterious force called "the Nothing" is spreading over the land of Fantastica, swallowing up its inhabitants in darkness. "Teaching the controversy" is really taking our students on a magical journey from life's collective humble beginnings as ribozymes in iron-sulfur cells to the early paths that split and fused along the open highways through the traffic jams and down the back alleys before arriving at our home. As the guide of this tour, simply "Do as you wish." Although humanity was never the end goal, we will naturally have a vested interest in understanding our story above all others. But remember, it is purely at your discretion when to take pit stops, where to pause for extended layovers, and to determine how much time will be devoted to sightseeing along the myriad of alternative paths, which I highly recommend, as it is a humbling experience to recognize that our tale is merely a needle in a haystack of other exciting and enriching stories the natural world has to offer. Of course, since this journal was designed with the purpose of serving as a conduit between the public education system and academia, it would be remiss of me not to address our needs as teachers.

Utterly vague and ridiculously specific ministry directives we have aplenty. What we need are the stories that bridge the curriculum. For instance, the students want to know (well, maybe just I do), if there's any evidence for, say, a transition from honeycomb "faveolar" lungs to the alveolar sacs of mammals? If we have to teach an exhaustive unit on the nervous system, we want to know where neuron cells might have originated, when myelin sheaths emerged, and so forth. We need explicit, clear narratives in addition to practical/affordable suggestions for labs and dissections to demonstrate some of the basic principles explored in each tale, and we want you to author 
them. Remember, the better trained we are, the more scientifically literate will be the rest of the voting population. But if you think this is just a one-way street, it's not. Academics, indeed, have the respected technical know-how, but we have the questions that can drive robust, popular, and socially meaningful research.

It may be hard to imagine when your entire field is being naively attacked in the press and scrutinized in courtrooms, but there is much to be gained from the drama that unfolds in the classroom. Take for instance the "bombardier beetle" fiasco of many years back. Instead of using the questions and criticisms generated by the public as a launching point for clear and focused research, biologists merely clarified the mechanism while whimsically speculating on the evolution of a defense system as elaborate as the pulsating cannon of the African bombardier beetle (Stenaptinus insignis). To date, I am not aware of a single phylogenetic study of bombardier beetles or the evolution of chemical defense within this clade (if it's even a monophyletic group). In fact, a search on the Web of Science has yet to reveal any meaningful research in this area in the last eight years! And yet the Internet debates rage on despite exciting preliminary studies of bombardier beetles that discharge a clinging froth (Metrius contractus) and non-pulsating mist (i.e., Crepidogaster ambreana and Crepidogaster atrata). Hmmm, seems almost "transitional," but that would be entirely speculative without a robust cladistic study. I smell a Nature publication for some opportunistic graduate student....

Even when they stumble, students teach us something. They make us question how we describe a process, whether or not we have indeed explained something well enough, and perhaps, most importantly, they can infuse academia with novel, lucrative, and (frankly) obvious questions that often aren't being asked regardless of the practical limitations. Students are simply armed with a tool that a $\mathrm{PhD}$ program cannot teach: imagination. Being their teachers, we are privy to the questions that may one day fuel exciting and new research, and the scientific community can only gain from collaborative outreach.

Nothing magically comes into existence, though the results can appear fantastical. Although our powers of biological resolution become fuzzier and more speculative the further we go back in time, our inferences are just as meaningful as the first images from the Hubble telescope before minor lens surgery. As I hope to demonstrate, the universal narrative can be an effective approach to teaching some of the more conceptually difficult concepts in biology. But it doesn't stop there. Our bodies, even our very atoms, have been on a truly wondrous journey through time. As astrophysicist Dr. Neil deGrasse Tyson once said, "We are connected to all life biologically, to the planet chemically, and the universe atomically." Our story is the epic of epics, one that spans the entire science curriculum, and it's just waiting to be discovered; pieced together by you, the respective guide (hopefully a better narrator) to valiantly keep this channel surfing generation tuned in long enough to hear a message that can be appreciated regardless of ideological bent: You are "a child of time," a living homage to a legacy nearly four billion years in the making, while the very atoms that make up your body, born of big bang and star dust, will journey on long after you've breathed your last breath, forever recycled and recombined like the ouroboros, an ode to the dual nature of the universechance and circumstance, matter and energy, creation and destruction. This is the Neverending Story. Consume it, digest it, meditate on it and, most importantly, pass it on. Don't be a Know Nothing.

\section{References and Further Reading}

Aledo JC. An early and anaerobic scenario for the transition to undifferentiated multicellularity. J Mol Evol. 2008;67:145-53.

Allen JF, Martin W. Out of thin air. Nature. 2007;445:610-2.

Brooks DR, McLennan DA. The nature of diversity: an evolutionary voyage of discovery. 1st ed. University of Chicago Press: Chicago; 2002.

Canfield DE, Rosing MT, Bjerrum C. Early anaerobic metabolisms. Philos Trans R Soc B. 2006;361:1819-36.

Carroll SB. Chance and necessity: the evolution of morphological complexity and diversity. Nature. 2001;409:1102-9.

Cunchillos C, Lecointre G. Ordering events of biochemical evolution. Biochimie. 2007;89:555-73.

Falkowski PG, Godfrey LV. Electrons, life, and the evolution of Earth's oxygen cycle. Philos Trans R Soc B. 2008;363:2705-16.

Falkowski PG, Isozaki Y. The story of $\mathrm{O}_{2}$. Science. 2008;322:540-2.

Feng S, Tian G, He C, Yuan H, Mu Y, Wang Y, et al. Hydrothermal biochemistry: from formaldehyde to oligopeptides. J Mater Sci. 2008;43:2418-25.

Forterre P. The two ages of the RNA world, and the transition to the DNA world: a story of viruses and cels. Biochimie. 2005;87:793-803.

Freilich S, Goldovsky L, Ouzounis CA, Thornton JM. Metabolic innovations towards the human lineage. BMC Evol Biol. 2008;8:247-60.

Gabaldon T, Huynen MA. From endosymbiont to host-controlled organelle: the hijacking of mitochondrial protein synthesis and metabolism. PloS Compu Bio. 2007;3:2209-18.

Gogarten JP, Fournier G, Zhaxybayeva O. Gene transfer and the reconstruction of life's early history from genomic data. Space Sci Rev. 2008;135:115-31.

Gregory TR. The evolution of complex organs. Evo Edu Outreach. 2008;1:358-89.

Hackstein JHP, Tjaden J, Huynen M. Mitochondria, hydrogenosomes, and mitosomes: products of evolutionary tinkering! Curr Genet. 2006;50:225-45.

Higgs PG, Pudritz RE. A thermodynamic basis for prebiotic amino acid synthesis and the nature of the first genetic code. Astrobiology. 2009;9:483-90.

Howe CJ, Barbrook AC, Nisbet RER, Lockhart PJ, Larkum AWD. The origin of plastids. Phil Trans R Soc B. 2008;363:2675-85.

Jalasvuori M, Bamford JKH. Structural co-evolution of viruses and cells in the primordial world. Orig Life Evol Biosph. 2008;38:165-81. 
Kiang NY et al. Spectral signatures of photosynthesis. I. Review of earth organisms. Astrobiology. 2007;7:222-51.

Kirschvink JL, Kopp RE. Palaeoproterozoic ice houses and the evolution of oxygen-mediating enzymes: the case for a late origin of photosystem II. Phil Trans R Soc B. 2008;363:2755-65.

Koch AL, Silver S. The first cell. Adv Microb Physiol. 2005;50:22759.

Koonin EV. The origin of introns and their role in eukaryogenesis: a compromise solution to the introns-early versus introns-late debate. Biol Direct. 2006;1:22-45.

Koop RE, Kirschvink JL, Hilburn IA, Nash CZ. The paleoproterozoic snowball Earth: a climate disaster triggered by the evolution of oxygenic photosynthesis. PNAS. 2005;102:11131-6.

Kulp TR. Arsenic (III) fuels anoxygenic photosynthesis in hot springs biofilms from Mono Lake, California. Science. 2008;321:967-70.

Kumala M, Brooks DR. The Neverending Story-The Origin and Diversification of Life. Evo Edu Outreach. 2010, Online First.

Kump RL. The rise of atmospheric oxygen. Nature. 2008;451:2778.

McLennan DA. The concept of co-option: why evolution often looks miraculous. Evo Edu Outreach. 2008;1:247-58.

Mentel M, Martin W. Energy metabolism among eukaryotic anaerobes in light of proterozoic ocean chemistry. Phil Trans R Soc B. 2008;363:2717-29.
Mulkidjanian AY, Makarova KS, Galperin MY, Koonin EV. Inventing the dynamo machine: the evolution of the F-type and V-type ATPases. Nat Rev. 2007;5:892-9.

Mulkidjanian AY, Galperin MY, Makarova KS, Wolf YI, Koonin EV. Evolutionary primacy of sodium bioenergetics. Biol Direct. 2008;3:13-31.

Robinson R. Jump-starting a cellular world: investigating the origin of life, from soup to networks. PloS Biol. 2005;3:1860-3.

Rokas A. The origins of multicellularity and the early history of the genetic toolkit for animal development. Annu Rev Genet. 2008;42:235-51.

Rothschild LJ. The evolution of photosynthesis...again? Phil Trans R Soc B. 2008;363:2787-801.

Russell MJ, Martin W. The rocky roots of the acetyl-CoA pathway. Trends Biochem Sci. 2004;7:358-63.

Russell MJ. The alkaline Solution to the emergence of life: energy, entropy, and early evolution. Acta Biotheor. 2007;55:133-79.

Saul JM, Schwartz L. Cancer as a consequence of the rising level of oxygen in the late precambrian. Lethaia. 2007;40:211-20.

Sleep NH, Bird DK. Evolutionary ecology during the rise of dioxygen in the Earth's atmosphere. Philos Trans R Soc B. 2008; 363:2651-64.

Szostak JW. Systems chemistry on early earth. Nature. 2009;459:171-2.

Thauer RK. A fifth pathway of carbon fixation. Science. 2007;318:1732-3. 